\title{
ESCRITURA Y CIUDAD EN MARÍA ZAMBRANO: REENCUENTRO DE UNA AMISTAD PERDIDA TRAS LA DERROTA SUFRIDA ${ }^{1}$
}

\author{
ANDREA LUQUIN CALVO \\ Universitat de València
}

\begin{abstract}
En este trabajo abordamos la reflexión que sobre el acto del escribir y la escritura realiza María Zambrano en sus escritos "Del escribir" y "Por qué se escribe", para relacionarlos con uno de los espacios más importantes para la pensadora: la ciudad. Aunque Zambrano no desarrolló una "teoría" sobre la ciudad propiamente dicha, su significado e imagen se encuentran en gran parte de su obra. La escritura, como logos que existe físicamente en el mundo, construye la ciudad: ese lugar de la palabra y de la libre expresión que nos protege. Una ciudad que parece derrotada ante la desaparición del pensamiento creativo, no instrumental, en el espacio público y que exige su reencuentro.

PALABRAS ClAVE: María Zambrano, escritor / escritora, ciudad, público lector, pensamiento crítico, exilio.

Writing and the City according to María Zambrano: Refinding a Lost Friendship After its Defeat

In this work we consider the reflections on the act of writing in María Zambrano's "Del escribir" and "Por qué se escribe", in order to link them with one of the most important spaces for the philosopher: the city. Although, strictly speaking, Zambrano did not develop a theory of the city, its meaning and representation are widely present in her work. Writing, as a logos that physically exists in the world, builds the city, that place of language and free expression that protects us. However, the city seems defeated by the absence of creative thinking in public spaces and demands its return.

KEY WORDS: María Zambrano, writer, city, reading public, critical thinking, exile.
\end{abstract}

Mucho se ha escrito sobre la relación que la filosofía y la poesía guardan para María Zambrano. ${ }^{2}$ Para la malagueña, tanto la filosofía como la poesía poseen

\footnotetext{
${ }^{1}$ El presente artículo tiene su origen en una comunicación presentada en el I Congreso de la Red Española de Filosofía (REF) en Valencia, en septiembre de 2014, dentro de la mesa "Filosofía y literatura en las pensadoras del siglo XX", coordinada por Neus Campillo Iborra.
} 
una misma raíz en la narración del mundo que realizan: la admiración ante la realidad que nos rodea. Pero esta admiración hacia el mundo es abordada de distintas maneras. Mientras que el filósofo se abstrae de la realidad (pues busca perseguir lo permanente y lo idéntico) y se encuentra dispuesto a salir de la cueva platónica en la búsqueda de esa idea única que sostiene al mundo, el poeta prefiere resguardarse entre las sombras y las luces: permanece apegado a la multiplicidad del espacio. El poeta, a diferencia del filósofo, aspira a construir un todo con "cada una de las cosas, sin abstracción ni renuncia alguna" (Zambrano, 1993: 22), respetando los matices del mundo que escapan a definiciones esquemáticas. Después de todo el ser humano, nos dice Zambrano, vive a la intemperie y, por ello, en ocasiones precisa de resguardarse en la cueva de la que nos expulsa Platón. En la narración que va construyendo el ser que somos son necesarias así las ficciones, las metáforas y los símbolos en que nos contamos, porque somos seres incompletos, no terminados, en posibilidades abiertas, no delimitados y cerrados. Esa es nuestra tragedia y, como el héroe trágico, buscamos descubrirnos en las infinitas y diversas narraciones que nos contamos, que nos rodean y que nos permiten aparecer en el espacio. De esta forma, tanto la filosofía como la poesía son ante todo ejercicios de escritura de nuestro mundo: de los caminos que trazamos para descubrir el ser que somos, de la narración de los seres, las cosas y sus relaciones que hacen su aparición en el mundo para permanecer en él gracias a la palabra escrita. Somos escritura, somos palabra.

La escritura es así un acto radical para encontrarnos en el mundo. Por la escritura la palabra hace su aparición en nuestro espacio y puede transformar a quien entra en su contacto: las palabras se leen por un otro y permanecen en el mundo justamente para ese otro. La escritura se encuentra así en el corazón del espacio no solo privado, sino también público. De esta forma, ambas palabras, la poética y la filosófica, deberían ser el corazón en la construcción de ese territorio que ocupamos y que posibilita una vida propiamente humana. Nos referimos a la ciudad, espacio que ocupa en el pensamiento de Zambrano un importante lugar.

La ciudad es el aquí, el paso, el presente con su diversidad de seres que escribe el poeta. Pero desde esa diversidad, el filósofo busca dirigirse al universal: no renuncia fundar con su escritura la ciudad ideal para todos. Por ello, escribir es un acto de libertad radical tan necesaria en el corazón de una ciudad: el pensamiento aparece en el espacio de la ciudad para hacerlo suyo, para ser

\footnotetext{
${ }^{2}$ Referente al tema abordado en el presente artículo, no podemos dejar de mencionar algunos importantes trabajos, entre los que destacan: María Zambrano. La literatura como conocimiento y participación, Lleida, Edicions de la Universitat de Lleida, 1997, de María Luisa Maillard, "La necesidad de escribir y la alquimia del pensamiento", Entre el alba y la aurora, Barcelona, Icaria, 2005, pp. 137-154, de Carmen Revilla Guzmán, "Filosofía y poesía. El 'doble tirón’ de la poesía y del pensamiento", Más allá de la Filosofía: sobre el pensamiento filosófico-místico de María Zambrano, Madrid, Trotta, 2000, pp. 215-250, de Ana Bundgård y María Zambrano, crítica literaria, Madrid, Devenir, 2004, de Goretti Ramírez.
} 
palabra y ser en el aquí, junto con el otro, porque a la vez desea fundar la ciudad, las estructuras, las casas y los edificios que protegen a todos. Escribir construye la polis. Para María Zambrano, la reconciliación armónica de la filosofía y la poesía debía de producir un pensamiento que habría de superar y transformar el racionalismo de la modernidad por el que hemos pagado un alto precio: nuestra propia cosificación en ciudades que han perdido su rostro humano. Hoy por hoy, podemos observar cómo poesía y filosofía son expulsadas de nuestros espacios: el acto creativo de la escritura, como medio de hacer presente lo ausente, de hacer presente nuevas formas de ser, desaparece de nuestras ciudades. La escritura instrumental, técnica, llena nuestros espacios. El pensamiento creativo, crítico, es silenciado: cuestionamos la necesidad y utilidad de la escritura abierta en nuestro mundo. Nuestras polis carecen de espacios para la escritura, para que nuevas formas de ser aparezcan en el espacio. Sutilmente, se nos ha derrotado, cosificado, anulado, justamente con nuestras propias palabras.

Por ello, queremos recuperar dos escritos que María Zambrano dedicó al acto mismo de la escritura, a esa búsqueda y encuentro de ficciones, metáforas y símbolos que todos necesitamos para resguardarnos, para construir nuestro espacio y su significado: nuestro lugar en la ciudad. La escritura como el corazón no solo de la ciudad, sino de la poesía, la literatura, la filosofía. La escritura como un acto eminentemente político, que hace polis. El primer texto corresponde a uno de sus primeros ensayos "Por qué se escribe" publicado en la Revista de Occidente, en 1934, cuando la filósofa tenía 29 años y que aborda el acto mismo del escribir. Un escrito realizado antes del exilio de la escritora. Este ensayo lo recuperaría en el año 1950 en su obra Hacia un saber sobre el alma. El segundo trabajo es una columna aparecida en el diario El País y posteriormente recogida en Las palabras del regreso, se titula "Del escribir" y se publicó en 1985, cincuenta años después de muchas escrituras y muchas vidas en el exilio. Consideramos que no es de extrañar que este trabajo dé un paso más allá al planteado en "Por qué se escribe" al subrayar la importancia del escritor y la escritura dentro de la ciudad, dentro del espacio público, espacio negado a la propia escritura de Zambrano durante su exilio, y que remite a una concepción eminentemente política del papel del escritor.

\section{Por qué se escribe: la reconquista de la derrota}

A la pregunta ¿Qué es escribir? Zambrano nos contesta en su texto "Por qué se escribe" (Zambrano, 2005: 35-44) que ante todo es "defender la soledad en que se está" (35). Estamos en soledad, a la intemperie, y abrazamos esa soledad aunque el mundo (con su sociedad del espectáculo y su consumo que llena nuestro espacio) trate de evitar que la sintamos. Esta irreductible soledad se traduce en lejanía, en distancia de todas las cosas y seres que "hace posible un descubrimiento de relaciones entre ellas" (35). La distancia permite obtener la perspectiva necesaria para visualizar el espacio que nos rodea, que nos muestra 
"lo que en ella y únicamente en ella, se encuentra" (35): un vacío lleno de posibilidades aún por aparecer en el mundo, gracias a la palabra escrita. La inmensidad se abre ante nosotros en la soledad de la escritura, una inmensidad que en la medición y el pensamiento absoluto, que reduce y limita a conceptos, no es posible encontrar. La escritura puede llenar el espacio vacío que nos rodea, volverlo a vaciar, cambiarlo, reconfigurarlo.

Por ello, desde esa inmensidad en que se instala, el escritor busca "las palabras que se nos han escapado traicionándonos" (42). Traicionándonos porque nos apartan de la multiplicidad y nos encarcelan en un único pensamiento. Hemos sufrido la derrota en nuestras palabras y en nuestros discursos que cosifican, limitan y encarcelan la diversidad del mundo. La escritura tiene el poder de mostrar nuevas palabras y existencias, de rescatar otras palabras de la traición que designan, señalándonos también el lugar donde se genera la traición. La escritura busca así "vencer por la palabra los instantes vacíos idos, el fracaso incesante de dejarnos ir por el tiempo" (42). El fracaso de dejarnos llevar por lo cotidiano, de envolvernos en discursos que niegan la multiplicidad del mundo y limitan nuestra capacidad de actuar y crear.

Zambrano se pregunta qué es lo que quiere decir el escritor con su palabra: "Quiere decir el secreto; lo que no puede decirse con la voz" — nos dice- "La verdad de lo que pasa en el secreto seno del tiempo, es el silencio de las vidas, y que no puede decirse" (38). Se trata de recuperar lo que calla el mundo, lo que no aparece en el espacio de la razón instrumental porque no tiene lugar donde aparecer, porque no puede enunciase. Esto, lo que no puede decirse en nuestros espacios, lo condenado al silencio en nuestras ciudades es, precisamente para Zambrano, "lo que se tiene que escribir" (38). Gracias a la escritura, la palabra no dicha pasa a perdurar y aparecer en el mundo físicamente. Por la escritura, la multiplicidad y creación de la vida reaparecen en nuestro espacio. Una presencia necesaria en un mundo que reduce y simplifica su multiplicidad, que aparta discursos y aleja a seres (recordemos el exilio de la filósofa) condenándolos al silencio, negándoles la palabra y con ello su presencia en el espacio. La importancia del escritor, de todo acto de escritura, se hace evidente: la palabra salva del olvido aquello que quedó en las orillas, en el afuera del gran camino de la historia.

La palabra escrita adquiere así una nueva dimensión de la que la palabra dicha carece. La palabra hablada, para Zambrano, brota de lo inmediato, como una reacción apremiante ante el mundo constituido, una necesidad que nos viene de afuera, de las circunstancias que nos envuelven. Una reacción condicionada, sin que seamos responsables de ella. Esta palabra hablada "no nos recoge, ni, por tanto, nos crea" (35). Se escapa con el propio tiempo en que se enuncia. En el hablar, simplemente "vencemos por la palabra al momento y luego somos vencidos por él [...]. Es una continua victoria que, al fin, se transmuta en derrota" (36). Se trata de la derrota de lo cotidiano, de nuestros condiciona- 
mientos, del día a día, sin espacio para nosotros, para instaurarnos en el mundo. Prisioneros de lo que hemos dicho, de los discursos impuestos, de los disfraces que utilizamos. Se trata de una derrota íntima, nos dice Zambrano, no solo del sujeto particular que somos, sino del propio ser humano, incapaz de abrazar lo múltiple, a la vida misma. Por ello, como señala la propia pensadora en La confesión, género literario, "[n]o se escribe ciertamente por necesidades literarias, sino por la necesidad que la vida [esa vida plural y múltiple, agregamos nosotros] tiene de expresarse" (Zambrano, 2004: 25).

La vida es siempre perdurable en la escritura. La palabra escrita hace su aparición física en nuestro mundo. Tinta y papel (memoria electrónica si se quiere hoy). En el acto de escribir una parte física se desprende de mí. Existe de forma independiente. Al escribir me inscribo en lo escrito, me desentraño en el acto creativo del lenguaje que se abre a miles de posibilidades que existen en mí y en el mundo, que aparecen en el espacio gracias a la palabra escrita. El tiempo no escapa más, pues logro atraparlo en el acto creativo de la escritura: sopeso lo que escribo, logrando que el tiempo forme parte de la propia construcción de la palabra. Al escribir, a diferencia del hablar, "se retienen las palabras, se hacen propias, sujetas a ritmo, selladas por el dominio humano de quien así las maneja [...]. Las palabras van así cayendo, precisas, en un proceso de reconciliación del hombre que las suelta reteniéndolas" (Zambrano, 2005: 36-37).

La exigencia de la escritura es así la necesidad de expresión de la vida, esa vida que se escapa y que busca reencontrarnos en las palabras: "Se escribe para reconquistar la derrota sufrida siempre que hemos hablado largamente. Y la victoria sólo puede darse allí donde ha sido sufrida la derrota, en las mismas palabras" (36). Es así que estas mismas palabras que nos han derrotado, poseen en la escritura una función distinta, pues "no estarán al servicio del momento opresor [...], sino que, partiendo del centro de nuestro ser en recogimiento, irán a defendernos ante la totalidad de los momentos, ante la totalidad de las circunstancias, ante la vida íntegra" (36). Por ello, nos señala Zambrano, "[t]oda victoria humana ha de ser reconciliación, reencuentro de una perdida amistad, reafirmación después de un desastre en que el hombre ha sido la víctima" (37). Por la escritura nos reencontramos, amistosa, amorosamente, de nuevo con el mundo. La caverna nos acoge de nuevo en medio de la intemperie a la que hemos sido arrojados.

La palabra es creadora y, por ello, descubridora de lo posible. Y lo posible y múltiple es el signo de la vida que se nos escapa en nuestras construcciones. El escritor así, nos dice Zambrano, va ganando terreno al mundo de lo inhumano, que sin cesar le presenta combate. En este combate, el escritor vence "en un glorioso encuentro de reconciliación con las tantas veces traidoras palabras" (37). El oficio del escritor busca así "salvar a las palabras de su momentaneidad, de su ser transitorio, y conducirlas en nuestra reconciliación hacia lo perdurable” (38), porque la vida es siempre perdurable en la escritura. 


\section{La comunidad de la escritura: acto de fe y fidelidad}

¿Para quién o para qué se escribe? se pregunta Zambrano. Si bien el escritor está solo, su soledad, nos dice, constituye un "aislamiento comunicable" (35). Si es la necesidad de expresión de la vida, de su derrota, lo que realmente impulsa la exigencia de la escritura, el escritor escribe para comunicar a los otros esta expresión porque en "rigor si se muestra a él, no es a él, en cuanto individuo determinado, sino en cuanto individuo del mismo género de los que deben conocerla [...], a quien en verdad se muestra es a esta comunicación, comunidad espiritual del escritor con su público" (42-43). De ahí la necesidad de comunicar que siente quien escribe: la necesidad de mostrar al otro la palabra escrita que le pertenece, la necesidad de un espacio público.

Existe así una comunidad entre el escritor y el público, que se forma, para nuestra pensadora, no después de que el público lee la obra publicada, sino antes, "en el acto mismo de escribir el escritor su obra" (43), pues el escritor es el instrumento de esa vida que le engloba a él y a los otros. Por ello, como señala Zambrano:

El público existe antes de que la obra haya sido o no leída, existe desde el comienzo de la obra, coexiste con ella y con el escritor en cuanto tal. Y sólo llegarán a tener público, en la realidad, aquellas obras que ya lo tuvieren desde un principio. $\mathrm{Y}$ así el escritor no necesita hacerse cuestión de la existencia de ese público, puesto que existe con él desde que comenzó a escribir. (43-44).

El escritor tropieza así, nos dice María Zambrano, con una verdad, la encuentra y la muestra, para "que sean ellos, su público, quienes desentrañen su sentido" (40). Porque ese sentido "no deja de ser secreto para él [el escritor] primero que para nadie" (40). La obra no será terminada nunca, como palabra creativa que es en sí misma: los sentidos de una obra son infinitos como sus lectores, como los momentos en que esos lectores se acercan a la obra escrita. Y su creatividad es tal que, una vez da a la luz la obra escrita, el propio escritor se encuentra con otra obra insospechada.

La obra, por lo tanto, no pertenece al escritor: pertenece a una comunidad entre lectores y escritores. Por ello, al publicar su obra, el escritor ignora el efecto que esta va a causar en esa comunidad. Escribir se convierte así, para Zambrano en un acto de fe. Es "como el lanzarse a algo cuya trayectoria no es por nosotros dominable" (40). Si el escritor publica es "para algo, para que alguien, uno o muchos, al saberlo, vivan sabiéndolo, para que vivan de otro modo después de haberlo sabido; para librar a alguien de la cárcel de la mentira, o de las nieblas del tedio, que es la mentira vital" (41).

Pero no solo escribir es un acto de fe, lo es también de fidelidad. Escribir es, nos dice Zambrano, "[s]er fiel a aquello que pide ser sacado del silencio" (40). Y 
esto implica que el escritor "no ha de ponerse a sí mismo, aunque sea de sí de donde saque lo que escribe. [...] La verdad necesita de un gran vacío, de un silencio donde pueda aposentarse, sin que ninguna otra presencia se entremezcle con la suya, desfigurándola" (40-41). El escritor, para Zambrano, no debe llamar a la vanidad: no necesita de premios o reconocimientos, porque la verdad que encuentra no es de su propiedad. La verdad encontrada tiene un público, lo tuvo siempre. Por ello, al verdadero escritor, nos dice la pensadora, le espera una gloria "que logra, cuando escuchando en su soledad sedienta con fe, sabe transcribir fielmente el secreto desvelado [...] después [...] de perseguir, capturar y retener las palabras para ajustarlas a la verdad" (43). Pero, como bien aclara Zambrano, "la gloria es en rigor de todos; se manifiesta en la comunidad espiritual del escritor con su público y la traspasa" (43). Por ello las obras literarias son universales y permanecen en el tiempo: siempre nos hablan.

$\mathrm{Y}$ así surge el objeto físico que se instaura en el mundo: el libro. En sus ensayos "Ser naciente" (Zambrano, 2009b: 185-187) y "El libro: ser viviente" (Zambrano, 2009c: 179-184), la autora nos señala, todas esas sensaciones que, a quienes amamos la lectura, nos produce la presencia de un libro. Cuando nos enfrentamos con un libro sea por primera vez, sea en una segunda mano, nos encontramos con que:

El libro no es sólo una colección de pensamientos, ni siquiera la forma privilegiada del pensar. Es un ser viviente [...]. Se nota su presencia física, respira ante todo, irradia, tiene número, o está sometido al número, al peso y a la medida. [...] El libro está, pues, de pleno, en la physis. Sin él, algo faltaría en la creación. Una criatura nada menos. Y el libro es, ante todo, buscado, saboreado, y despide un particular olor. [...] Una hoja de un árbol puede ser un libro, y en ocasiones lo es. (185)

"El libro existe de por sí, lleva su ser propio, tiene su hueco, tiene su ausencia, tiene su amor" (Zambrano, 2009c: 179). El escritor así siente el ansia de comunicar, de publicar, de producir un efecto, que alguien se entere de algo: publica un libro. Pero un libro, mientras no se lee, nos dice Zambrano, "es solamente ser en potencia, tan en potencia como una bomba que no ha estallado. $\mathrm{Y}$ todo libro ha de tener algo de bomba, de acontecimiento que al suceder amenaza y pone en evidencia, aunque sólo sea con su temblor, a la falsedad" (2005: 39).

\section{Filosofía y literatura: la belleza de la forma}

Es así que el verdadero escritor, nos recuerda Zambrano, retomando el tema de la escritura en su texto de 1985, "Del escribir" (Zambrano, 2009: 191-195), "es el que a solas clama a los cielos, el que se arriesga, porque de ello tiene el mandato: un mandato de expresar, y en la forma más indeleble posible, aquello que clama a los cielos. Y éste es el escritor" (194). No es extraño que en este artículo, realizado 
después de su exilio y a su regreso a España, Zambrano recupere la fuerza del escritor como depositario de un mandato clave en ese espacio de ausencias en que se convierte la polis.

Hay dos maneras de realizar este mandato. Una es la filosofía. Otra la escritura, la literatura. En realidad, todo filósofo es escritor, pues como nos dice la propia Zambrano en su artículo "Del escribir", "[n]inguna obra clásica de filosofía deja de ser [...] una obra literaria de primer orden" (2009: 191). Tanto es así, nos recuerda, que hay casos de obras filosóficas que se presentan principalmente como únicas, más por su contenido literario que filosófico. Lo curioso es que este tipo de obras son infravaloradas por los propios filósofos: se señalan directamente como literatura, apartadas del pensamiento "rígido" o "lógico" y son consideradas, erróneamente en muchas ocasiones, una especie de parafilosofía. Ironía, nos dice Zambrano, pues aquellos que las condenan no se percatan de que, precisamente, es la belleza literaria la que permite que el pensamiento filosófico se revele en una mayor claridad y sea, sobre todo, también comunicable. Como expresa la pensadora malagueña, el perjuicio a la belleza de la escritura literaria (vuelta a la caverna platónica), hace que el pensamiento filosófico que no sea expresado en una forma "académica" sea despreciado como literatura. "Y así se da rienda suelta al doble maleficio que condena al pensamiento y a la belleza" — nos dice- "pues que así se menosprecia aquel descubrimiento a medias logrado, impidiéndolo crecer, mientras que se confunde la belleza literaria con lo que puede ser estrechez de forma o también la ampulosidad de una ya usada retórica" (191-192).

La propia obra de María Zambrano sufre esta paradoja. En muchas ocasiones, y erróneamente a nuestro entender, su pensamiento es considerado "menor" dentro del discurso filosófico: la escritura de Zambrano es acto creativo que no renuncia a la belleza expresiva, a la metáfora y al símbolo. Una escritura rechazada por la filosofía más ortodoxa. Pero, como lo señala la propia filósofa, es el propio pensamiento español el que ha sido desdeñado constantemente, precisamente por mostrase bajo las formas artísticas (literatura, pintura) y no ante la heterodoxia de una razón excluyente. Pensamiento al margen que, hoy por hoy, nos dice Zambrano en su obra Pensamiento y poesía en la vida española (Zambrano, 2004b), puede dar una respuesta a un pensamiento que, bajo la razón instrumental, se nos presenta sin salida. Porque quizás la filosofía, con su heterodoxia y su alejamiento del mundo, forma parte de la derrota sufrida. Por ello, María Zambrano denunciaba de qué modo la filosofía necesita de la poesía, pues solamente ésta permitirá alcanzar ese conocimiento profundo, capaz de dejar atrás el racionalismo de la modernidad y su concepto de razón, por el que hemos pagado un alto precio. Una nueva escritura debe abrirse paso en nuestros espacios para transformar la ciudad. Una escritura como acto de fe y fidelidad de la que nuestros espacios públicos, nuestras ciudades, parecen tan necesitadas. Y ese es el tema que late en "Del escribir". 


\section{La ciudad y el escritor: un reencuentro deseado}

Debemos recordar que la ciudad ha sido, para Zambrano, el lugar por excelencia para las creaciones humanas. "La ciudad es lo que más se acerca a la persona" —nos dice la filósofa— “[t]iene figura, rostro, fisonomía” (Zambrano, 1994: 163). Un lugar que como sitio de memoria y significación, como "comunión con los que fueron y que dejaron su nombre y la impronta de su vivir" (164), logra convertir el espacio en lugar de significaciones capaces de crear una morada que nos proteja. La ciudad es, pues, un escenario de la historia. Es ahí donde la historia, el diálogo entre la criatura humana y el universo, se hace, generando sentido. Por ello, nos dice Zambrano, la ciudad no es solo historia, sino lugar de algo que la engendra. La ciudad permite la aparición de ese quién que somos en el mundo, bajo un conjunto de creaciones y significados que dan paso a nuestra existencia. La ciudad es así también "lugar de la palabra" pues la polis es "el espacio de la discusión, de la libre expresión del pensamiento; el espacio donde el pensamiento, la palabra, existe por primera vez" (Zambrano, 1988: 105-106).

Pero, para María Zambrano, la ciudad moderna se ha convertido en un espacio amenazante, pues su construcción se basa en su razón instrumental capaz de dominar y controlar el mundo y a sus habitantes, olvidando la relación originaria de cuidado y protección que debía de cimentarla. Los fenómenos totalitarios, así como el exilio que había vivido nuestra pensadora, son muestra de ello. La ciudad es de este modo vivida como una construcción capaz de negar las aspiraciones y los deseos del individuo. La pérdida de la ciudad como lugar posible de nuestra aparición, se traduce en un paulatino extrañamiento del individuo respecto de la comunidad. Esta pérdida es indicio, para Zambrano, de que algo pasa en las raíces de la cultura occidental pues "es cosa en extremo grave este desvanecimiento casi completo de la creencia en la ciudad y del vivir por ella inspirado" (1994: 163). Por ello, no sin razón, Zambrano nos presenta a La tumba de Antígona en los propios cimientos de la polis (1989: 219). Se trata de los cimientos de una ciudad por la que, debido a sus leyes, a la narración que la construye, Antígona se encuentra condenada en la tumba desde la que nos habla. En la obra de nuestra pensadora, Antígona se confronta con las leyes de la ciudad que la condena, de la ciudad vacía y ausente donde su palabra quiere ser borrada. Y lo hace así, porque la palabra hace aparecer lo que no tiene lugar en el espacio, en nuestras ciudades: lo que ha sido anulado y apartado de ella. Y, no por casualidad, quien hace este alegato a favor de la palabra en la ciudad no es un filósofo, sin una heroína literaria, una heroína trágica.

María Zambrano señala, respecto al papel de la filosofía en la ciudad, cómo sin lugar a dudas ocupa un lugar importante en su ordenamiento: "Diógenes con su tonel estaba en una ciudad. Filosofar, pues, debe ser cosa muy esencial para la ciudad, para que la haya" (2009: 195). Pero mientras el filósofo en su tonel permanece aislado y no sale al encuentro de la ciudad, el escritor, como el héroe trágico, sí lo hace. Se sumerge en el mundo, entra en la ciudad creando lo que 
puede llegar a ser, señalando lo que ha quedado olvidado, en sus ruinas y sus tumbas: la traición de las palabras, de nuestras construcciones y discursos. Percibe sus matices, la singularidad, no renuncia a lo que ve en las sombras. Por ello, "[u]na ciudad sin escritor es un templo vacío, una plaza sin centro, o quizá con el centro desplazado y puesto al margen, esquinado, para dejar su lugar, todo el lugar, a algo cuyo nombre no está siquiera bien catalogado, algo para lo que, en realidad, no hay palabra" (192) nos dice María Zambrano, agregando que "[e]l escritor es imprescindible para que aun aquello que en la ciudad ocurra, y clame al cielo, no se quede oculto bajo el silencio opaco, para que salte clamando a los cielos [...], el escritor sería el corazón de la ciudad, su centro el único que podría rescatar a la ciudad de haber sido desposeída de su centro, allanada en verdad" (195).

Por eso necesitamos de la escritura, de esa escritura viva y creativa, apegada al espacio. Es el rencuentro tras una amistad perdida, la del propio ser humano con otros y con el mundo: el rencuentro para trazar las calles, las casas y el mapa de la ciudad de otra forma, abriendo en la ficción lo posible, lo que aún puede llegar a ser, lo que quedó en el afuera de la ciudad, apartado a la orilla del camino y que merece ser el corazón de la ciudad, de nuestra polis. "El escritor es así el verdadero mediador, invisible a veces" (192), que nos muestra otras formas de existencia que abarcan lo diverso: una diversidad que rescata la esencia del proteger la vida. Por ello " $[\mathrm{u}]$ na ciudad sin escritores queda vaciada de su esencia de ciudad, y aparece como un complejo aglomerado, como algo que puede cambiarse, transmutarse o desaparecer sin que su vacío se note" (192).

En este sentido, la escritura se une con la historia, con ese diálogo del ser con el mundo en busca de su lugar. Por ello, señala Zambrano, el escritor brilla y renace en determinados periodos de la historia. Especialmente, la filósofa hará hincapié, como no podría ser de otra forma, en la historia europea. "Hasta se podría decir que el escritor haya sido uno de los actores esenciales del vivir europeo" —nos dice- " [e]l escritor ha sido [...] el espejo de Europa. Espejo en un sentido activo, pues que no se conformaba con reflejar la imagen, sino con crearla y recrearla una y otra vez" (192-193). Para Zambrano "Europa [...] se ha ido haciendo a sí misma, en pluralidad y unidad" (193). Y en ello llama constantemente a la escritura, pues solo esa creatividad puede dar respuestas en los momentos de agonía que sacuden al viejo continente. Para nuestra pensadora, debido al racionalismo instrumental, Europa ha perdido la capacidad de proyectarse, de crear nuevos horizontes. No hay palabras que abran nuestro espacio a otras posibilidades, a la esperanza, a esa utopía signo del pensamiento occidental.

En esa Europa que agoniza, Zambrano encuentra que el escritor y su figura están devaluados. No solo sería ya la figura del filósofo, de ese Diógenes en su tonel o encerrado en su despacho, en su mundo de ideas alejado cada vez más de la calle, sino el del creativo, el escritor, ese contador de historias y creador de 
existencias a quien estamos perdiendo. Zambrano cree que "la decadencia de su función" (192) se encuentra en relación a "la disolución, o disgregación que parece ir en creciente, de la especificidad de Europa, de la pérdida de su identidad y de su cambiante figura dentro de la unidad" (193). María Zambrano nos lleva a pensar una escritura con proyecto, con sentido, que permita de nuevo la construcción de una Europa como ciudad abierta, libre y democrática, como espacio y lugar de la palabra. Una ciudad que comienza como esa utopía que solo puede aparecer por primera vez en nuestros espacios, gracias a la palabra, a la escritura capaz de compartir con el otro. Una escritura que forma una comunidad capaz de realizarla. Sin embargo, hoy más que nunca, cuando parece que la construcción de esa Europa se tambalea, nos encontramos con que despreciamos al escritor, a las humanidades, al pensamiento en creación: despreciamos a aquellos que nos muestran otra forma de ver la ciudad, de recrear Europa. Nos convencen de que hemos sido derrotados: no podemos más que seguir los designios que nos imponen los pensamientos delimitados, escuchando discursos que no entendemos, perdidos en un hablar incesante. No habitamos en ciudades de escritores: son malos tiempos para la lírica.

Reencontrarnos ante la derrota sufrida es el papel y la tarea de la literatura, de la escritura, de todo pensamiento alternativo a la realidad de nuestras ciudades actuales cada vez más deshabitadas, cada vez más carentes de ese rostro humano por el que clamaba Zambrano. Debemos ayudar a sacar a nuestras ciudades de la decadencia, del silencio, de la tumba sin tiempo a la que se nos condena. Hemos hablado demasiado, toca el tiempo del escribir; de hacer un acto de fe y fidelidad con nosotros mismos, con los habitantes de la ciudad.

Ese es el llamado que María Zambrano nos hace al recordarnos la enorme fuerza que posee ese acto tan sencillo, pero tan creativo y subversivo, como es el escribir.

\section{REFERENCIAS BIBLIOGRÁFICAS}

Zambrano, María (1989), Senderos. Los intelectuales en el drama de España. La tumba de Antígona, Barcelona, Anthropos.

-(1993), Filosofía y Poesía, Madrid, Fondo de Cultura Económica.

-(1994), España sueño y verdad, Madrid, Siruela.

-(1988), Persona y Democracia, Barcelona, Anthropos.

-(2000), La agonía de Europa, Madrid, Trotta.

-(2004), La confesión: Género literario, Madrid, Siruela.

-(2004b), Pensamiento y poesía en la vida española, Madrid, Biblioteca Nueva.

-(2005), "Por qué se escribe", Hacia un saber sobre el alma, Madrid, Alianza: 3544.

-(2009), "Del escribir”, Las palabras del regreso, Mercedes Gómez Blesa (ed.), Madrid, Cátedra: 191-95. 
—(2009b) "Ser naciente", Las palabras del regreso, Mercedes Gómez Blesa (ed.), Madrid, Cátedra: 185-87.

-(2009c) "El libro ser viviente", Las palabras del regreso, Mercedes Gómez Blesa (ed.), Madrid, Cátedra: 179-84.

\section{(c) (i) $(9)$}

